\title{
Viabilidade de Sclerotinia sclerotiorum após a Solarização do Solo na Presença de Cobertura Morta*
}

\author{
Leila C. L. Ferraz ${ }^{1}$, Armando Bergamin Filho ${ }^{1}$, Lilian Amorim ${ }^{1} \&$ Luiz C. B. Nasser ${ }^{2}$ \\ ${ }^{1}$ Departamento de Entomologia, Fitopatologia e Zoologia Agrícola, Escola Superior de Agricultura \\ "Luiz de Queiroz", Universidade de São Paulo, CEP 13.418-900, Piracicaba, SP, fax: (019) 3434-4839, \\ e-mail: 1ferraz@esalq.usp.br; ${ }^{2}$ Centro de Pesquisa Agropecuária do Cerrado, Empresa Brasileira de \\ Pesquisa Agropecuária, Cx. Postal 08223, CEP 73.301-970, Planaltina, DF, fax: (061) 389-2953
}

(Aceito para publicação em 20/11/2002)

Autor para correspondência: Leila C. L. Ferraz

FERRAZ, L.C.L., BERGAMIN FILHO, A., AMORIM, L. \& NASSER, L.C.B. Viabilidade de Sclerotinia sclerotiorum após a solarização do solo na presença de cobertura morta. Fitopatologia Brasileira 28:017-026. 2003.

\section{RESUMO}

O efeito de diferentes temperaturas no solo e de diversas palhas sobre o solo na viabilidade dos escleródios de Sclerotinia sclerotiorum foi estudado em estufa. Em três ensaios de campo, estudou-se a solarização do solo associada à presença de palha de milho (Zea mays) sobre o solo na viabilidade de escleródios, durante três meses. Ensaios de campo foram realizados em Piracicaba e em Brasília. Escleródios foram produzidos em meio cenoura+fubá, e incorporados ao solo (ensaios em estufa), ou acondicionados em invólucros, e enterrados no solo a 5, 10 e 30 $\mathrm{cm}$ (ensaios no campo). Os tratamentos de solo no campo foram: solarizado $(S)$, não solarizado (NS) e solarizado com adição de palha de milho $(P S)$. Foram feitas avaliações a cada 30 dias, em meio NEON, observando a viabilidade e a presença de contaminantes nos escleródios. O aquecimento do solo em estufa a 50 e $60{ }^{\circ} \mathrm{C}$ com diversas palhas inativou os escleródios, que tiveram maior incidência de contaminantes. No campo, o efeito da solarização do solo foi significativo, inviabilizando os escleródios enterrados a diferentes profundidades: em $S$ após 90 dias, nas três profundidades, e em $P S$, após 60 dias, a 5 e $10 \mathrm{~cm} \mathrm{de}$ profundidade. A incidência de escleródios contaminados em solos solarizados foi maior em $S$, seguido de $P S$. A maior variabilidade de contaminantes, porém, foi observada em $P S$. As temperaturas do solo em $P S$ foram maiores quando comparadas aos outros tratamentos na mesma profundidade. Este fator proporcionou a redução do tempo da inativação dos escleródios de 90 dias em $S$, para 60 dias em $P S$.

Palavras-chave adicionais: controle físico, palha de milho, contaminantes.

\section{ABSTRACT}

Viability of Sclerotinia sclerotiorum after soil solarization in the presence of crop mulch

The effects of temperatures and crop mulch on topsoil in the inactivation of the sclerotia of Sclerotinia sclerotiorum were studied by oven heating in three field experiments during three months. Field experiments were performed in Piracicaba and in Brasília. Sclerotia were produced in a carrot+cornmeal medium, incorporated into the soil (oven-heating), conditioned in nylon bags, and buried in the soil at 5,10 and $30 \mathrm{~cm}$ (field). The soil treatments in the field were: solarization (S), non-solarization (NS), and solarized soil added to crop mulch $(P S)$. Sclerotia samples were collected every 30 days to observe the viability and presence of contaminants in NEON medium. The oven heating of the soil at 50 and $60^{\circ} \mathrm{C}$ and the use of diverse crop mulch inactivated the sclerotia, which had a higher incidence of contaminants. In the field, the effect of soil solarization was significant. The sclerotia were killed in $S$ after 90 days at three depths in the first experiment and in $P S$ after 60 days at 5 and $10 \mathrm{~cm}$ in the other two experiments. The incidence of contaminants in sclerotia in solarized soils was significantly higher in $S$, followed by $P S$; however, a greater variability of contaminants was observed in $P S$. Temperatures of the soil in $P S$ were higher when compared to the other treatments at the same depth. This factor reduced the inactivating time of the sclerotia from 90 days in $S$, to 60 days in $P S$.

\section{INTRODUÇÃO}

Sclerotinia sclerotiorum (Lib.) de Bary é um fungo de ampla ocorrência em todo o mundo, com pelo menos 408 espécies de plantas hospedeiras (Boland \& Hall, 1994). O controle desse patógeno em diversas culturas tem sido difícil

\footnotetext{
* Projeto apoiado pela FAPESP. Parte da tese de Doutorado da primeira autora . Escola Superior de Agricultura "Luís de Queiroz", Universidade de São Paulo (2001).
}

devido a sua capacidade de formar estruturas de resistência (escleródios), que garantem sua sobrevivência por vários anos, mesmo em condições adversas, limitando a utilização de práticas como a rotação de culturas. Na maioria das situações, não há disponibilidade de cultivares resistentes e o controle químico nem sempre é eficiente.

A técnica de solarização do solo tem sido estudada desde 1970, com resultados positivos para diversos patógenos veiculados pelo solo, inclusive para $S$. sclerotiorum (Porter 


\section{L.C.L. Ferraz et al.}

\& Merriman, 1985; Katan \& DeVay, 1991; Souza, 1994). A solarização consiste na utilização da energia solar para a desinfestação do solo previamente umedecido, por meio da cobertura com filme plástico transparente, possibilitando a inativação de diversos patógenos através do aquecimento do solo. E esta inativação pode também estar associada à ação de microrganismos com potencial para o controle biológico, tolerantes a altas temperaturas, aumentando a eficiência dessa prática (Katan \& DeVay, 1991).

A adição de resíduos orgânicos ao solo, associada à solarização, tem recebido a atenção de diversos autores. Pythium ultimum Trow foi controlado em alface (Lactuca sativa L.) combinando-se a solarização e a incorporação de composto de cama-de-frango ao solo (Gamliel \& Stapleton, 1993b). O efeito da incorporação ao solo de restos culturais, associada ou não à solarização, foi também estudado com relação a Verticillium dahliae Kleb., Phytophthora cinnamomi Rands, Pratylenchus penetrans (Cobb) Filipjev \& SchuurmansStekhoven e Agrobacterium rhizogenes (Riker et al.) Conn. O controle de $P$. cinnamomi $V$. dahliae foi obtido nos tratamentos com solarização isoladamente, e com solarização mais incorporação de restos culturais. Somente a incorporação de restos culturais não apresentou controle para esses patógenos. Porém, a redução das populações de $P$. penetrans e A. rhizogenes somente foi efetiva com a solarização do solo empregada isoladamente (Pinkerton et al., 2000). Pythium ultimum e Sclerotium rolfsii Sacc. tiveram suas populações reduzidas em solo aquecido ao qual se incorporou resíduo de repolho (Brassica oleracea $\mathrm{L}$. var. capitata L.). Entretanto, a simples adição de resíduo de repolho sem aquecimento não produziu resultado satisfatório (Gamliel \& Stapleton, 1993a). Nessa mesma linha, Lodha et al. (1997) demonstraram que a combinação da incorporação ao solo de resíduos de crucíferas e a cobertura do solo com polietileno controlouMacrophomina phaseolina (Tassi) Goidanich, provavelmente devido ao aumento de populações de bactérias antagônicas.

O emprego de cobertura morta sobre o solo associado à prática de solarização não tem recebido a atenção dos pesquisadores até o presente momento. Em virtude dessa prática ser de mais fácil emprego pelos agricultores, quando comparada à incorporação de resíduos, este trabalho teve como objetivo investigar o efeito da combinação da solarização e da adição de diferentes tipos de palha sobre o solo na viabilidade de escleródios de S. sclerotiorum.

\section{MATERIAL E MÉTODOS}

Foram realizados ensaios em condições controladas com objetivo de determinar as temperaturas letais para a inativação de escleródios de S. sclerotiorum. O aquecimento do solo foi testado isoladamente e em associação com a deposição de cobertura morta sobre o solo. O efeito da solarização do solo no campo, aplicado isoladamente, ou em associação com cobertura com palha de milho (Zea mays L.), na viabilidade de escleródios de S. sclerotiorum foi testado em ensaios de campo.
Efeito do aquecimento do solo na viabilidade dos escleródios de $S$. sclerotiorum

Dois ensaios foram realizados em condições controladas. No primeiro ensaio, escleródios de S. sclerotiorum do isolado UnB-916, colhidos de plantas de ervilha (Pisum sativum L.) em Brasília-DF, após serem submetidos à assepsia (3 min em álcool a 50\% e 3 min em hipoclorito de sódio a $1 \%$ ), foram incubados por sete dias em placas contendo meio de BDA (batata-dextrose-ágar) com estreptomicina. Após esse período, o micélio proveniente dos escleródios foi repicado para meio cenoura+fubá (Ferraz \& Café Filho, 1998) e incubado durante um período de 30 dias, no escuro, a $20 \pm 2{ }^{\circ} \mathrm{C}$. Os escleródios produzidos foram separados do meio por lavagem e secos ao ar. Escleródios foram incorporados ao solo proveniente de área previamente cultivada com feijoeiro (Phaseolus vulgaris L.). O solo infestado foi colocado em bandejas de alumínio, umedecido com água destilada e, após três dias, incubado por $24 \mathrm{~h}$ em estufas mantidas a temperaturas de 40,50 e $60{ }^{\circ} \mathrm{C}$. Após esse período, os escleródios permaneceram no mesmo solo à temperatura de $20 \pm 3{ }^{\circ} \mathrm{C}$, por três dias. Os escleródios foram, então, coletados, lavados em água corrente e submetidos a um processo de assepsia ( 3 min em álcool a $50 \%$ e 3 min em hipoclorito de sódio a $1 \%$ ). Os escleródios foram avaliados quanto à viabilidade em meio semi-seletivo NEON (Nasser et al., 1995), incubados a $18{ }^{\circ} \mathrm{C}$ no escuro. A viabilidade foi observada após sete dias, por meio da mudança de cor do meio de violáceo para amarelo. Adicionalmente, escleródios mantidos em meio NEON por um período de três dias a $22{ }^{\circ} \mathrm{C}(12 \mathrm{~h}$ luz/12 h escuro) foram avaliados quanto à incidência de contaminantes, observados em estereomicroscópio e em microscópio óptico. A avaliação foi realizada em quatro placas de Petri com cinco escleródios. Os resultados foram comparados com os tratamentos de escleródios acondicionados em geladeira a $4{ }^{\circ} \mathrm{C}$ pelo mesmo período. Foram também realizadas observações ao microscópio eletrônico de varredura para verificar alterações morfológicas na superfície dos escleródios.

$\mathrm{O}$ segundo ensaio investigou o efeito de diversas temperaturas do solo $\left(20,30,40,50\right.$ e $\left.60^{\circ} \mathrm{C}\right)$ na viabilidade dos escleródios de $S$. sclerotiorum. Vasos de alumínio de 18 $\mathrm{cm}$ de diâmetro por $15 \mathrm{~cm}$ de altura foram preenchidos com solo proveniente de área cultivada com feijoeiro. A mesma metodologia de produção de escleródios descrita anteriormente e o mesmo isolado foram utilizados. O solo foi infestado com 50 escleródios, incorporados a $5 \mathrm{~cm}$ de profundidade. Os vasos foram mantidos a $20 \pm 3{ }^{\circ} \mathrm{C}(12 \mathrm{~h}$ luz/12 h escuro $)$ durante 40 dias e irrigados duas vezes por semana. Após esse período, os vasos foram mantidos por $8 \mathrm{~h}$ em estufa, com temperaturas ajustadas para cada tratamento, com o objetivo de obter a temperatura almejada por um período de $4 \mathrm{~h}$, de acordo com monitoramento por termômetros no solo. Ao serem retirados da estufa, os vasos foram mantidos a $20 \pm 3$ ${ }^{\circ} \mathrm{C}$. Após $24 \mathrm{~h}$, foram acrescidos ao solo $100 \mathrm{ml}$ de água destilada, e os vasos retornaram a estufa nas mesmas temperaturas dos tratamentos. Esse processo foi repetido por três dias consecutivos. Após este processo os vasos foram mantidos a 
Viabilidade de Sclerotinia sclerotiorum após a solarização do solo...

$20 \pm 3{ }^{\circ} \mathrm{C}$ por três dias adicionais. Antes e depois de submetidos ao período de incubação em estufa foram coletadas amostras de 15 escleródios por vaso, e colocados em número de cinco escleródios por placa de Petri contendo o meio de cultura semi-seletivo NEON. Seguiu-se a mesma metodologia descrita no primeiro ensaio, tanto para assepsia e plaqueamento, quanto para a avaliação da viabilidade e da incidência de contaminantes. $\mathrm{O}$ experimento foi instalado com delineamento inteiramente casualizado com quatro repetições, e cada amostra de 15 escleródios coletados de cada vaso de alumínio, antes e depois do processo de aquecimento, correspondeu a uma repetição.

Efeito de diversas palhas em solo aquecido na viabilidade de escleródios de $S$. sclerotiorum

Neste ensaio avaliou-se o efeito da adição, sobre o solo aquecido em estufa, das palhas de niger [Guizotia abyssinica (L.f.) Cass], feijoeiro, milho, milheto [Pennisethum glaucum (L.) R. Br.] e quinoa (Chenopodium quinoa Wild.) na viabilidade de escleródios de $S$. sclerotiorum. O procedimento de execução e avaliação foi o mesmo do ensaio anterior. Em vasos de alumínio contendo solo, as palhas foram colocadas sobre a superfície do solo na espessura de $6 \mathrm{~cm}$, e esses mantidos úmidos por 40 dias. Após este período os vasos contendo os diversos tratamentos foram mantidos em uma temperatura única de incubação $\left(50{ }^{\circ} \mathrm{C}\right)$ por $4 \mathrm{~h}$ em três dias consecutivos. A assepsia, o plaqueamento, a avaliação da viabilidade e da incidência de contaminante foram semelhantes ao relatado no ensaio anterior. O experimento foi instalado em delineamento inteiramente casualizado com quatro repetições, e cada amostra de 15 escleródios coletada de cada vaso de alumínio, antes e depois do processo de aquecimento, correspondeu a uma repetição.

Viabilidade de escleródios de $S$. sclerotiorum após a solarização do solo - $\mathbf{1}^{0}$ ensaio de campo

Este experimento foi realizado em Piracicaba-SP, na latitude de 22\%42'30"sul, longitude de 47038'00"oeste, e altitude de $546 \mathrm{~m}$, durante 90 dias, a partir de 20 de outubro de 1997. Procedeu-se a produção dos escleródios de $S$. sclerotiorum com o mesmo isolado e a mesma metodologia utilizadas nos ensaios anteriores. Os escleródios foram acondicionados em invólucros de malha de nylon perfurada (15 escleródios/invólucro) e enterrados nas profundidades de 5 , 10 e $30 \mathrm{~cm}$. Os locais de enterrio estavam separados uns dos outros por cerca de $60 \mathrm{~cm}$. O solo foi irrigado previamente até a saturação e coberto com plástico transparente de 100 $\mu \mathrm{m}$ de espessura. Conjuntos de invólucros contendo escleródios foram enterrados em parcelas não cobertas com plástico (tratamento "não solarizado" - NS) e em parcelas de solo cobertas com plástico (tratamento "solarizado"- $S$ ). Os solos dos diversos tratamentos foram monitorados quanto à temperatura, utilizando geotermômetros anexados a um coletor de dados (Campbell 21X). Foram realizadas coletas periódicas dos invólucros durante o experimento após 30, 60 e 90 dias. Os escleródios foram avaliados quanto à viabilidade e presença de contaminantes como descrito nos ensaios anteriores.

O experimento foi instalado em delineamento inteiramente casualizado em esquema fatorial em três profundidades $(5,10$ e $30 \mathrm{~cm})$ e em três épocas de avaliação (30, 60 e 90 dias), com três repetições. Cada invólucro contendo 15 escleródios correspondeu a uma repetição. Os tratamentos solarizados e não solarizados abrangeram uma área de $80 \mathrm{~m}^{2}$ cada um.

Viabilidade de escleródios de $S$. sclerotiorum após a solarização do solo na presença de palha de milho sobre o solo - $2^{\circ}$ e $3^{\circ}$ ensaios de campo

Um dos ensaios foi instalado em 16 de dezembro de 1998 e conduzido por 90 dias, em Piracicaba-SP (2 $2^{\circ}$ ensaio de campo). Utilizaram-se os mesmos tratamentos do ensaio anterior, adicionando-se o tratamento de cobertura do solo com palha de milho e solarização do solo (PS). As metodologias foram semelhantes às utilizadas no ensaio anterior.

No tratamento $P S$, a superfície do solo foi coberta com palha de milho, com $6 \mathrm{~cm}$ de altura. Após a deposição da palha, as parcelas foram molhadas até a saturação do solo e, em seguida, cobertas com plástico transparente de $100 \mu \mathrm{m}$ de espessura. Parcelas controle foram cobertas com plástico, mas sem palha $(S)$. As parcelas experimentais tiveram a dimensão de 2 × $2 \mathrm{~m}$, e o conjunto de três invólucros nas três profundidades foram enterrados distanciados $60 \mathrm{~cm}$ uns dos outros, dentro de uma mesma parcela. As parcelas experimentais ficaram distantes entre si por $1,00 \mathrm{~m}$. A temperatura do solo foi monitorada nas diferentes profundidades por meio de sensores de temperatura do solo anexados a um coletor de dados (Campbell 21X), obtendo-se a média das temperaturas a cada $30 \mathrm{~min}$

Outro ensaio foi realizado em Brasília-DF ( $3^{\circ}$ ensaio de campo), na latitude de $15^{\circ} 35^{\prime} 30^{\prime}$ 'sul, longitude de $47^{\circ} 42^{\prime}$ 30"'oeste, e altitude de $1007 \mathrm{~m}$, a partir de 8 de setembro de 1999, durante 90 dias. Os tratamentos foram os mesmos do ensaio anterior, além de mais um tratamento com cobertura do solo somente com palha de milho $(P)$. As mesmas metodologias descritas para os ensaios anteriores foram utilizadas. As parcelas experimentais tiveram a dimensão de $1,80 \times 2,00 \mathrm{~m}$, e estas estavam distanciadas a 1,00 m uma das outras. A temperatura do solo foi monitorada nas diferentes profundidades, pelo enterrio de sensores de solo anexado a um termógrafo, obtendo-se a média diária das temperaturas.

Os experimentos foram instalados em blocos ao acaso em esquema fatorial [tratamentos do solo ( $N S, S, P S$ e $P$ ); profundidades $(5,10$ e $30 \mathrm{~cm})$ nas parcelas e épocas $(30,60$ e 90 dias) nas subparcelas], com quatro repetições. Cada invólucro contendo 15 escleródios correspondeu a uma repetição.

\section{RESULTADOS}

Efeito do aquecimento do solo na viabilidade dos escleródios de $S$. sclerotiorum

No primeiro ensaio todos os escleródios submetidos 


\section{L.C.L. Ferraz et al.}

às temperaturas de 40,50 e $60{ }^{\circ} \mathrm{C}$ por $24 \mathrm{~h}$ foram mortos, enquanto que aqueles incubados em geladeira $\left(4^{\circ} \mathrm{C}\right)$ apresentaram viabilidade entre 98 e $100 \%$. Não foi observada a presença de contaminantes nos escleródios provenientes de incubação em geladeira a $4{ }^{\circ} \mathrm{C}$. A incidência de contaminantes nos escleródios submetidos às diversas temperaturas foi de 22,82 e $18 \%$, respectivamente a, 40,50 e $60{ }^{\circ} \mathrm{C}$. Nos escleródios submetidos a 40 e $60{ }^{\circ} \mathrm{C}$ foi observada a predominância de bactérias e de fungos, tais como Penicillium spp. e Aspergillus spp. Nos escleródios aquecidos a $50^{\circ} \mathrm{C}$ observouse somente a presença de Penicillium spp.

$\mathrm{O}$ exame em microscopia eletrônica revelou a presença de rachaduras externas nos escleródios, as quais estavam recobertas de bactérias (Figura 1 A e B). Os escleródios não contaminados, provenientes do tratamento a temperatura de $4{ }^{\circ} \mathrm{C}$, permaneceram intactos, sem danos na camada do anel de proteção externa (Figura $1 \mathrm{C}$ ).

No segundo ensaio, os escleródios submetidos às temperaturas de 20,30 e $40{ }^{\circ} \mathrm{C}$, após $4 \mathrm{~h}$ por três dias, apresentaram viabilidade entre 98 e $100 \%$, e incidência de contaminantes de, no máximo, 1,6\%. Os escleródios aquecidos a 50 e $60{ }^{\circ} \mathrm{C}$ apresentaram viabilidade de 18 a $0 \%$, e incidência de escleródios contaminados de 83 a 100\%. Os escleródios coletados antes do aquecimento apresentaram viabilidade de 85 a $97 \%$, e contaminação de 2 a $20 \%$, diferindo estatisticamente dos tratamentos com aquecimento $(p \leq 0,05)$ (Figura 2 A e B). Foi observada a presença de bactérias e de fungos, tais como Penicillium spp.e Fusarium spp, como contaminantes, principalmente nos escleródios aquecidos a 50 e $60{ }^{\circ} \mathrm{C}$.

Efeito de diversas palhas em solo aquecido na viabilidade de escleródios de $\mathrm{S}$. sclerotiorum

Os escleródios advindos dos tratamentos com diversas palhas e aquecidos em estufa apresentaram viabilidade de zero a $12 \%$, com contaminação de 88 a $100 \%$. Esses valores foram significativamente diferentes $(p \leq 0,05)$ daqueles obtidos nos tratamentos sem aquecimento. Os escleródios provenientes dos tratamentos com palha e não aquecidos apresentaram viabilidade de 57 a $97 \%$, e incidência de

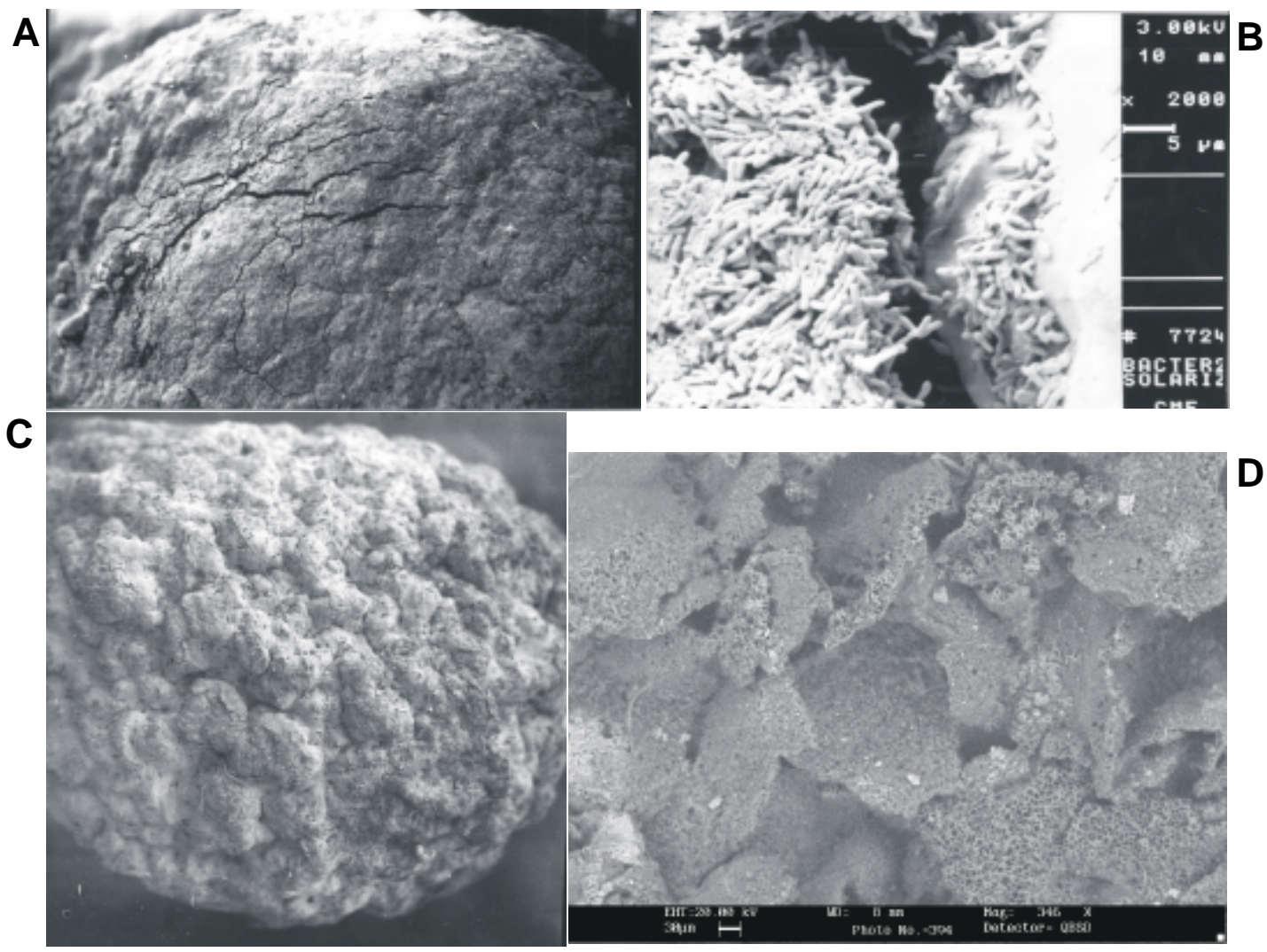

FIG. 1 - Efeitos sobre escleródios de Sclerotinia sclerotiorum. (A) Rachaduras observadas em escleródios (300 Kv, $9 \mathrm{~mm}, 25 \mathrm{x}, 500 \mu \mathrm{m})$ e (B) bactérias observadas em rachaduras do mesmo escleródio anterior, incubado por $24 \mathrm{~h}$ em solo aquecido à temperatura de $60{ }^{\circ} \mathrm{C}$, referentes ao $1^{\circ}$ ensaio do efeito do aquecimento do solo na viabilidade dos escleródios; (C) aspecto externo de escleródio e hifas não contaminados $(5 \mathrm{kV}, 8 \mathrm{~mm}, 2000 \mathrm{x}, 5 \mu \mathrm{m})$, observados em escleródio incubado à temperatura de $4^{\circ} \mathrm{C}$; (D) Escleródio observado após 90 dias do processo de solarização na presença de palha de milho (Zea mays) sobre o solo (magnitude $346 \mathrm{x}$ ), referente ao $2^{\circ}$ ensaio de campo. 
Viabilidade de Sclerotinia sclerotiorum após a solarização do solo...

escleródios contaminados de 2 a $42 \%$ (Figura 2 C e D). Observou-se maior variabilidade de contaminantes presentes em escleródios submetidos ao aquecimento, com a predominância de bactéria e fungos dos gêneros Fusarium e Penicillium, quando comparados aos tratamentos não aquecidos e àqueles provenientes de solo aquecido sem a presença de palha do ensaio anterior.

Escleródios não submetidos ao aquecimento e advindos do tratamento de palha de quinoa apresentaram viabilibilidade de $57 \%$ e incidência de escleródios contaminados de $42 \%$. Essa drástica redução da viabilidade e maior incidência de contaminantes não foi observada nos outros tratamentos não submetidos ao aquecimento (Figura $2 \mathrm{C}$ e D).

Viabilidade de escleródios de $S$. sclerotiorum após a solarização do solo $-1^{0}$ ensaio de campo

Na coleta realizada aos 60 dias, a viabilidade dos escleródios situou-se entre 67 e $84 \%$ em solos solarizados $(S)$, e entre 87 e $98 \%$ nos solos não solarizados $(N S)$. Ao final de 90 dias, os escleródios estavam totalmente degradados no tratamento $S$, indicando a morte dos escleródios.

A análise de variância dos resultados de viabilidade e incidência de contaminantes nos escleródios indicou que o tratamento de solarização do solo, a data de coleta e a interação entre essas duas variáveis apresentaram diferenças significativas $(p \leq 0,05)$ (Figura 3 A)

O número de escleródios contaminados e a variabilidade de contaminantes foram crescentes dos 30 aos 60 dias para os escleródios advindos de $S$. Aos 90 dias, porém, não foi possível observar o número de escleródios contaminados, pois os escleródios estavam totalmente degradados (Figura 3 B). Os contaminantes mais freqüentes foram Penicillium spp.e Gliocladium spp.

Viabilidade de escleródios de $S$. sclerotiorum após a solarização do solo na presença de palha de milho sobre o solo - $2^{\circ}$ e $3^{\circ}$ ensaios de campo

No $2^{\circ}$ ensaio de campo, os escleródios advindos de $P S$ apresentaram viabilidade, após 60 dias, de 0 e 4\%, respectivamente, nas profundidades de 5 e $10 \mathrm{~cm}$. Após 90 dias, nenhum escleródio estava viável em todas as profundidades. Nas amostras provenientes de $S$ não foi observado um decréscimo considerável da viabilidade dos escleródios aos 60 e 90 dias (em média, 84 e $80 \%$, respectivamente)
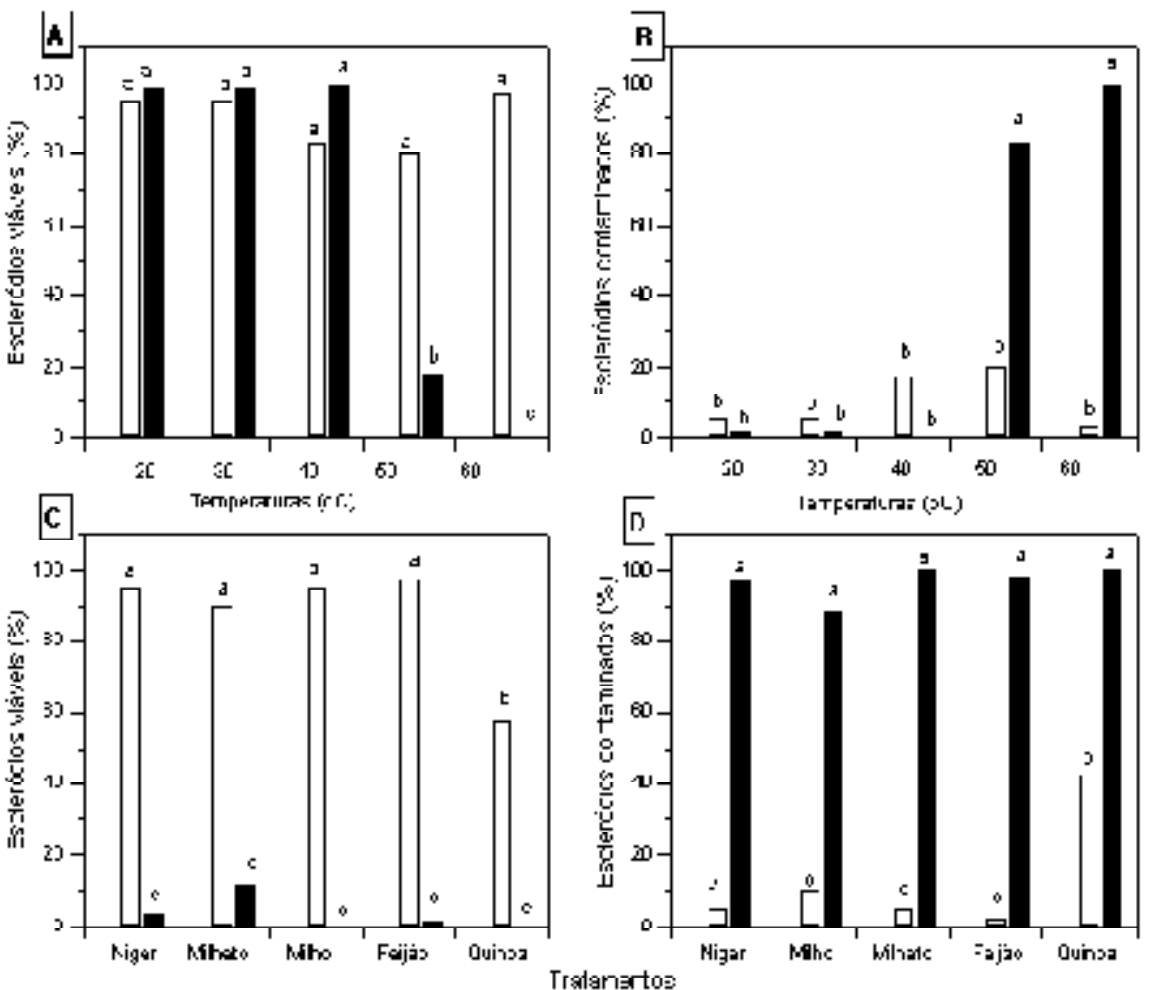

FIG. 2 - Efeitos sobre escleródios de Sclerotinia sclerotiorum. (A) Escleródios viáveis e (B) escleródios contaminados, referentes ao $2^{\circ}$ ensaio do efeito do aquecimento do solo na viabilidade dos escleródios; (C) escleródios viáveis e (D) escleródios contaminados referentes ao ensaio de efeito de diversas palhas em solo aquecido na viabilidade de escleródios. (Amostras provenientes do solo, coletadas nas mesmas parcelas: $\square$ antes do processo de aquecimento, $\square$ após o processo de aquecimento; em estufa). Barras referidas de mesma letra, acima das barras, não diferem estatisticamente entre si (Tukey $p \leq 0,05)$. 

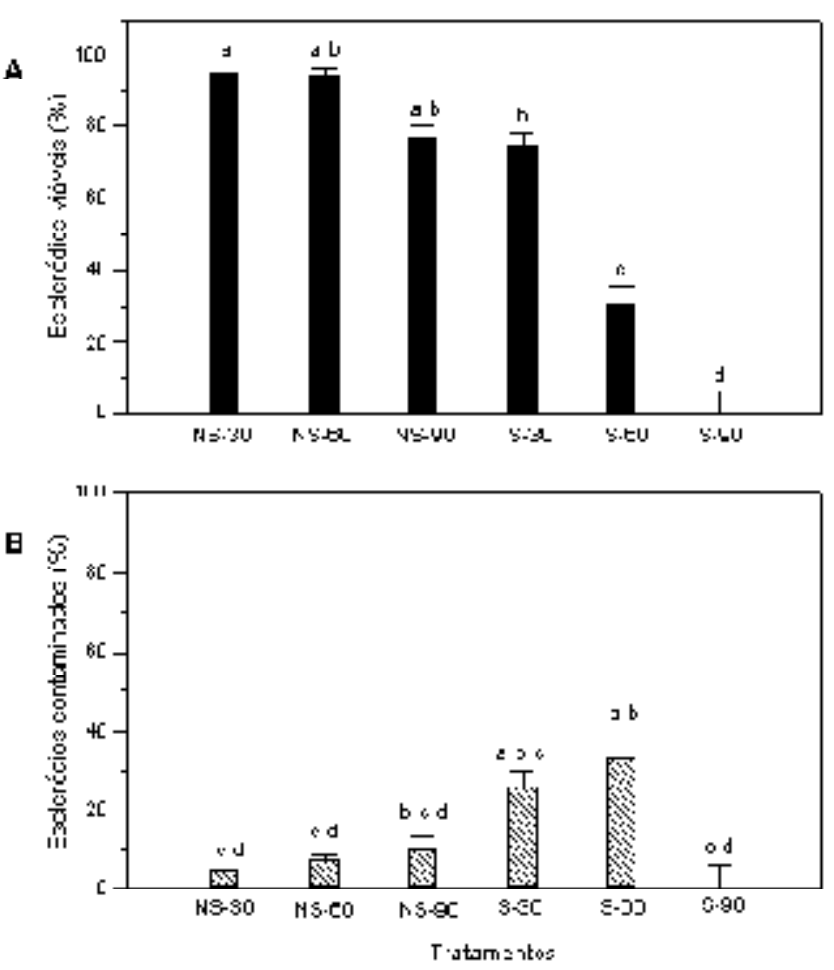

FIG. 3 - Efeitos sobre escleródios de Sclerotinia sclerotiorum. (A) Viabilidade de escleródios após sete dias de incubação em meio semi-seletivo NEON; (B) Escleródios contaminados após dez dias de incubação em meio semi-seletivo NEON, referente a interação de solarização do solo $(S=$ =solarizado, $N S=$ não solarizado) com a data de coleta $(30,60$ e 90 dias) ( $1^{\circ}$ ensaio de campo). Barras referidas de mesma letra, acima das barras, não diferem estatisticamente entre si (Tukey $p \leq 0,05$ ).

(Figura 4 A). A viabilidade dos escleródios no tratamento $N S$ variou de 87 a $100 \%$ nas diferentes profundidades.

Observou-se grande variabilidade de contaminantes nas três datas de coleta, principalmente nos escleródios submetidos à solarização $(P S$ e $S)$. Os contaminantes mais freqüentes foram Penicillium spp.e Fusarium spp.aos 30 dias, Fusarium spp.e Trichoderma spp.aos 60 dias e Fusarium spp.e Gliocladium spp.aos 90 dias. O anel de proteção dos escleródios submetidos à solarização em $P S$, na data final de coleta apresentou alterações (Figura $1 \mathrm{D})$.

O $3^{\circ}$ ensaio de campo, realizado em Brasília, apresentou resultados similares aos observados no ensaio anterior conduzido em Piracicaba. A viabilidade dos escleródios nos tratamentos $P S$ nas profundidades de 5 e $10 \mathrm{~cm}$ foi diminuída após 60 dias (entre 5 a 7\%). Aos 90 dias ocorreu inativação total dos escleródios nas profundidades de 5 e $10 \mathrm{~cm}$ e redução da viabilidade $(8,3 \%)$ a $30 \mathrm{~cm}$. A viabilidade dos escleródios em $S$ após 60 dias oscilou entre 18 e $48 \%$, e entre 10 e $36 \%$ aos 90 dias, nas três profundidades. Observaram-se diferenças significativas de viabilidade com a solarização do solo, a data de coleta, a interação desses fatores, e a interação entre profundidade de enterrio e solarização do solo $(p \leq 0,05)$ (Figura 5 A e B). Maior inativação dos escleródios foi observada a 5 e $10 \mathrm{~cm}$ nos tratamentos $S$ e $P S$.

A incidência de escleródios contaminados após 30 dias foi de $87 \%$ para $S$, e de $80 \%$ para $P S$. Maior número de escleródios contaminados foi observado, respectivamente, nos tratamentos $P S$ e $S$, nas profundidades de 5 e $10 \mathrm{~cm}$. Observaram-se diferenças significativas quanto à incidência de escleródios contaminados para as interações entre solarização e data de coleta, profundidade de enterrio e solarização do solo $(p \leq 0,05)$ (Figura $5 \mathrm{C}$ ). Muitos escleródios coletados aos 60 e 90 dias estavam degradados. Isto resultou em um número menor de escleródios avaliados nessas datas. Os contaminantes mais freqüentes foram Fusarium spp., Trichoderma spp., Verticillium spp.e Gliocladium spp. Observou-se maior variabilidade de contaminantes no tratamento de solo solarizado na presença palha de milho, quando comparado ao solo somente solarizado, tanto em Piracicaba ( $2^{\circ}$ ensaio) quanto em Brasília ( $3^{\circ}$ ensaio).

Nos dois ensaios realizados em Piracicaba, a radiação global oscilou na amplitude entre 100 e $700 \mathrm{cal} / \mathrm{cm}^{2} / \mathrm{dia}$ e a insolação diária, entre 0 e 18 h/dia. No ensaio realizado em Brasília, a radiação global variou entre 200 e $700 \mathrm{cal} / \mathrm{cm}^{2} / \mathrm{dia}$ e a insolação solar entre 0 e 11,5 h/dia.

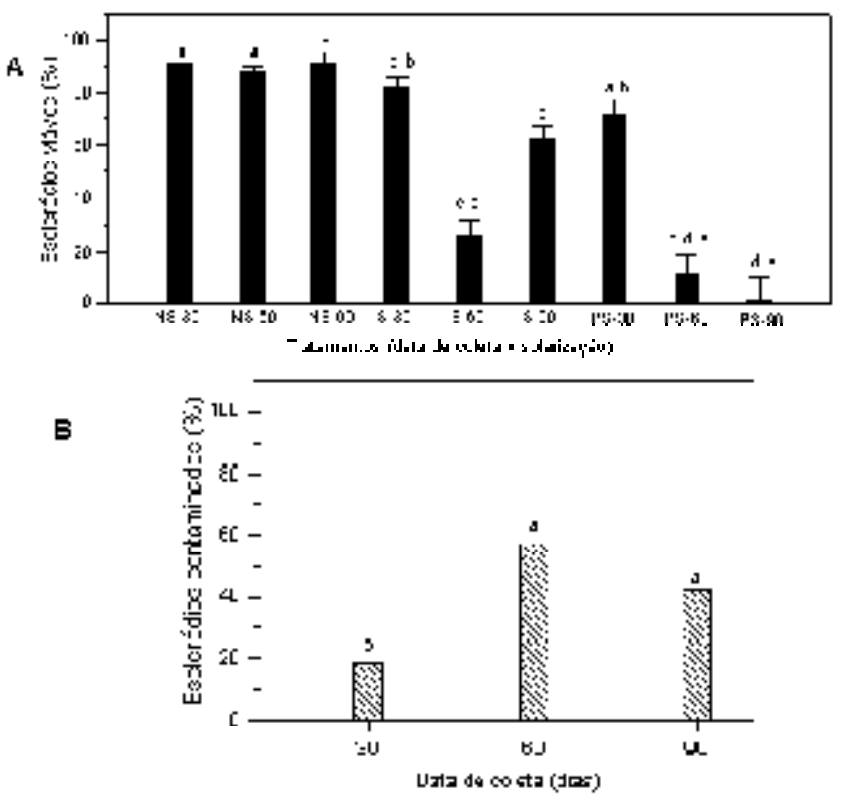

FIG. 4 - Efeitos sobre escleródios de Sclerotinia sclerotiorum. (A) Viabilidade de escleródios após sete dias de incubação em meio semi-seletivo NEON, referente a interação dos fatores de solarização do solo ( $S=$ solarizado, $N S=$ não solarizado, $P S=$ solarizado com palha de milho) $x$ data de coleta $(30,60$ e 90 dias); (B) Escleródios contaminados após dez dias de incubação em meio semi-seletivo NEON, referente a data de coleta ( $2^{\circ}$ ensaio de campo). Barras referidas de mesma letra, acima das barras, não diferem estatisticamente entre si (Tukey $p \leq 0,05)$. 
Viabilidade de Sclerotinia sclerotiorum após a solarização do solo...
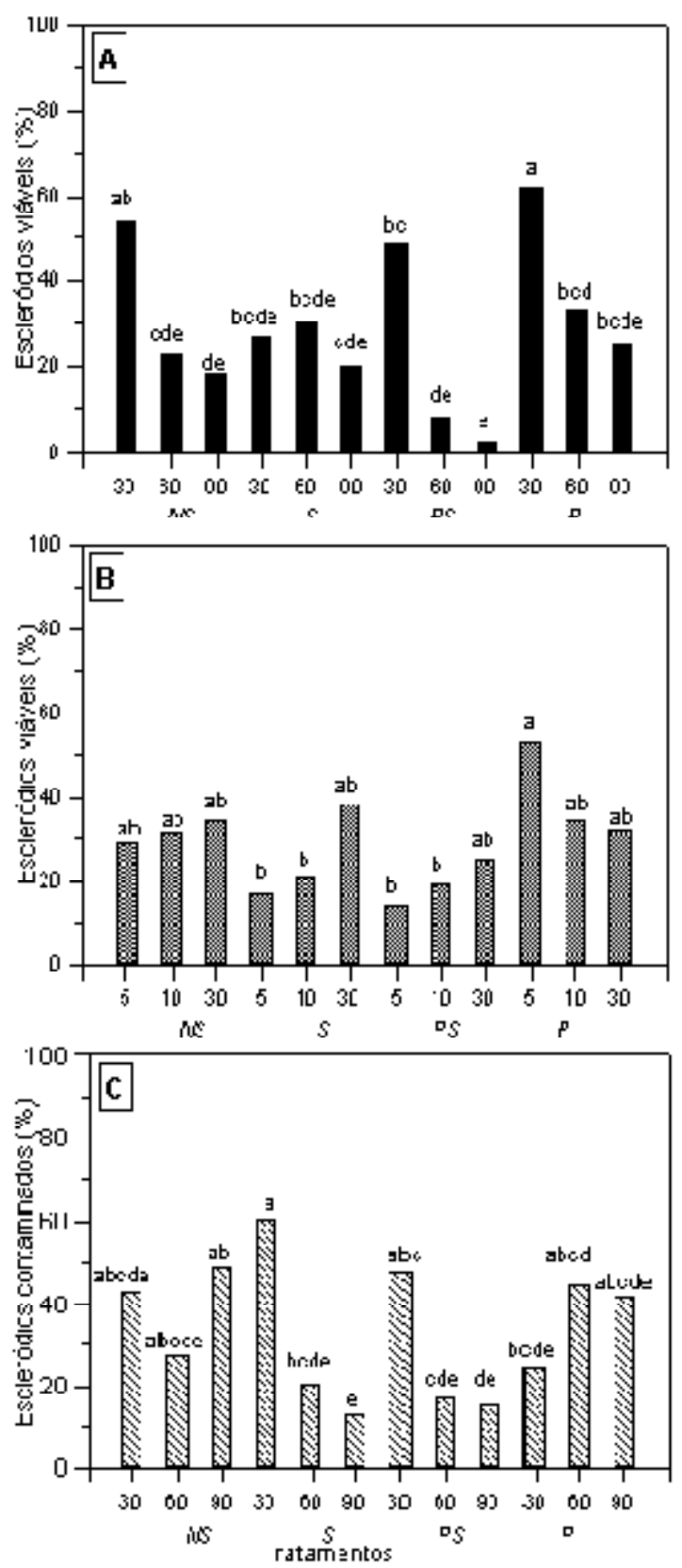

FIG. 5 - Efeitos sobre escleródios de Sclerotinia sclerotiorum. (A) Viabilidade de escleródios após sete dias de incubação em meio semi-seletivo NEON, referente à interação dos fatores de solarização do solo $(S=$ solarizado, $N S=$ não solarizado, $P S=$ solarizado com palha de milho, $P=$ coberto com palha de milho) $x$ data de coleta ( 30,60 e 90 dias); (B) Viabi lidade de escleródios após sete dias de incubação em meio semi-seletivo NEON, interação dos fatores de solarização do solo $x$ profundidade de enterrio $(5,10$ e $30 \mathrm{~cm})$; (C) Escleródios contaminados após dez dias de incubação em meio semi-seletivo NEON, interação dos fatores de solarização do solo $x$ data de coleta $\left(3^{\circ}\right.$ ensaio de campo). Barras referidas de mesma letra, acima das barras, não diferem estatisticamente entre si (Tukey $p \leq 0,05)$.
A média de temperatura de solo submetido à solarização a $5 \mathrm{~cm}$ de profundidade esteve em torno de $35,2{ }^{\circ} \mathrm{C}$ em $S$, no primeiro ensaio. No segundo ensaio, essa média foi de $31,6^{\circ} \mathrm{Cem} P S$ e de $29,9^{\circ} \mathrm{C} \mathrm{em} S$. As médias de temperatura a $5 \mathrm{~cm}$ de profundidade no ensaio instalado em Brasília foram de $26,9^{\circ} \mathrm{C}$ em $P S$ e $26,2^{\circ} \mathrm{C}$ em $S$. A amplitude térmica entre as temperaturas médias dos solos, nas três profundidades, $S$ e $S P$ com as temperaturas médias ocorridas no ar apresentaram diferenças de $10,8{ }^{\circ} \mathrm{C}$, em média referente ao tratamento $S$, no $1^{\circ}$ ensaio; $6,2^{\circ} \mathrm{C}$ em $P S$ e $4,5^{\circ} \mathrm{C}$ em $S$, no $2^{\circ}$ ensaio; e 5,0 ${ }^{\circ} \mathrm{C}$ em $P S$, e $4,3{ }^{\circ} \mathrm{C}$ em $S$, no $3^{\circ}$ ensaio.

As temperaturas máximas do ar foram as que mais se aproximaram às temperaturas ocorridas nos solos solarizados, apresentando curvas similares de variação durante o dia. Resultados parecidos foram observados entre as temperaturas médias diárias do ar e do solo não solarizados. Nos solos não solarizados não foram observadas grandes diferenças de temperatura de acordo com a profundidade, porém estas foram marcantes em $P S$ e $S$, principalmente a 5 e $10 \mathrm{~cm}$. A presença de palha sobre o solo e também coberto com plástico $(P S)$ conferiu um aumento da temperatura do solo em relação ao solo somente solarizado $(S)$, em média de 1,7 e $2,8^{\circ} \mathrm{C}$, respectivamente a 5 e $10 \mathrm{~cm}$, no $2^{\circ}$ ensaio; e de 0,7 e $2,2{ }^{\circ} \mathrm{C}$, respectivamente a 5 e $10 \mathrm{~cm}$, no $3^{\circ}$ ensaio (Figura 6). Entretanto, este acréscimo entre $P S$ e $S$ não foi constante no $3^{\circ}$ ensaio, em alguns períodos as temperaturas em $S$ foram maiores do que em $P S$ nas profundidades de 5 e $10 \mathrm{~cm}$ (Figura $6 \mathrm{C}$ ).

\section{DISCUSSÃO}

A ação de temperaturas elevadas, acima de $40{ }^{\circ} \mathrm{C}$, em solos aquecidos em estufa provocou redução drástica na viabilidade dos escleródios. Nestes tratamentos houve maior incidência de contaminantes, indicando que o aumento da temperatura favoreceu a população de microrganismos termofílicos do solo. A presença de fissuras no anel de proteção dos escleródios submetidos ao aquecimento, demonstrou o dano físico nas estruturas causado pelo calor. A constatação de bactérias nestas fissuras indicou que esse ambiente é favorável à proliferação bacteriana, provavelmente pela presença de exsudados dos escleródios, aumentando a eficiência da solarização. Resultados similares foram obtidos para escleródios de S. rolfsii (Lifshitz et al., 1983). Segundo Katan \& DeVay (1991), o aumento de temperaturas letais ou a ocorrência de temperaturas subletais cumulativas podem causar rachaduras nos escleródios, ocasionando a liberação de compostos ricos em carbono, que podem aumentar a colonização por outros microrganismos.

Apesar de não ter sido objeto de estudo elucidar o tempo de exposição à temperatura letal a escleródios de $S$. sclerotiorum, observou-se que períodos menores de exposição requereram temperaturas mais elevadas para o controle eficiente deste patógeno. Segundo Katan \& DeVay (1991) a temperatura de $37^{\circ} \mathrm{C}$ é o limite de temperatura letal para diversos fungos mesófilicos, sendo necessária uma exposição de duas a quatro semanas nesta temperatura para o controle 

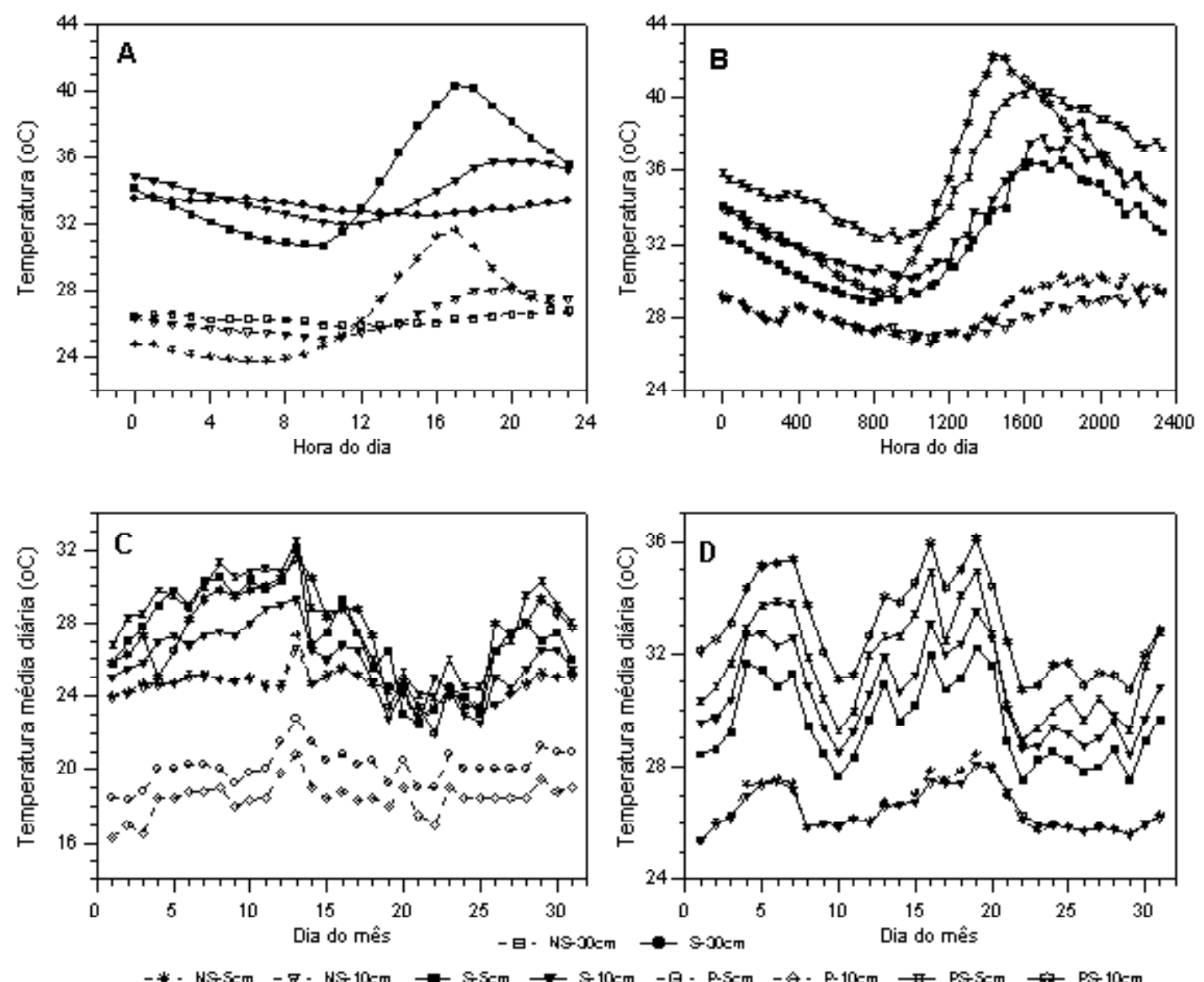

FIG. 6 - Temperaturas do solo observadas nos tratamentos do solo $[S=$ solarizado, $N S=$ não solarizado, $P S=$ solarizado com palha de milho, $P=$ coberto com palha de milho (Zea mays)] e nas profundidades de enterrio (5, 10 e $30 \mathrm{~cm}$ ), durante: (A) o dia 24/12/1997 (a cada 60 min.) no $1^{\circ}$ ensaio de campo (Piracicaba); (B) o dia 19/02/1998 (a cada $30 \mathrm{~min}$.) no $2^{\circ}$ ensaio de campo (Piracicaba); (C) o segundo mês (médias diárias) do $3^{\circ}$ ensaio de campo (Brasília); (D) o segundo mês (médias diárias) do $2^{\circ}$ ensaio de campo (Piracicaba).

desses fungos. Entretanto, a $47^{\circ} \mathrm{C}$, um período menor de cerca de 1 a 6 h de exposição é suficiente para ocasionar a morte dos propágulos. Porém escleródios de S. sclerotiorum, por serem multicelulares, possivelmente possuem maior número de mecanismos de reparo a injúrias, quando comparados a estruturas unicelulares, como a maioria dos microrganismos avaliados em outros trabalhos. Portanto, temperaturas mais elevadas que $37{ }^{\circ} \mathrm{C}$ ou períodos mais extensos de exposição são necessários para ocorrer a total inativação dos escleródios. Porém, em campo a dinâmica de aquecimento do solo é bem diferenciada, o que se observa é uma flutuação gradual do aquecimento do solo durante o dia, com ocorrência de temperaturas mais elevadas em curto período (cerca de 3 a 4 h) (Figura 6 A e B). Acredita-se, portanto, que a ocorrência de determinada temperatura letal, ou o acúmulo de temperaturas subletais possa ocasionar o controle deste patógeno na prática de solarização do solo.

A presença de todas as palhas avaliadas (milho, milheto, feijão, niger e quinoa) em solo aquecido na estufa contribuiu para inativar o patógeno em estudo. No solo aquecido a $50{ }^{\circ} \mathrm{C}$ descoberto não houve controle tão eficiente como com a presença de palha sobre o solo. Evidências de maior incidência e variabilidade de contaminantes nos escleródios desses tratamentos, em comparação ao tratamento de $50{ }^{\circ} \mathrm{C}$ sem adição de palha, sugerem a atuação de microrganismos que são favorecidos nesse processo.

A maior eficiência do aquecimento do solo solarizado devido à presença de palha pode também estar associada a substâncias fungitóxicas, tais como gases, liberados pela palha. Segundo Smith et al. (1993), quando os restos vegetais degradam-se, principalmente em solos úmidos, fermentações anaeróbias ocorrem, resultando na formação de ácidos acético, propiônico e butírico com concomitante decréscimo no $\mathrm{pH}$ do solo. Esses ácidos orgânicos podem ser tóxicos a plantas e a microrganismos em concentrações milimolares. Mesmo quando diversas fontes de matéria orgânica são incorporadas ao solo, antes da cobertura do solo com plástico, o controle de patógenos é atribuído à anaerobiose conferida pelo sistema 
Viabilidade de Sclerotinia sclerotiorum após a solarização do solo...

(Blok et al., 2000; Souza, 2001). Uma hipótese é que o processo de degradação da palha associada ao aumento da temperatura, pode ter otimizado a produção de compostos fungitóxicos.

A palha de quinoa apresentou redução da viabilidade do patógeno em estudo, independentemente do aquecimento do solo. Algumas cultivares de quinoa podem apresentar alta concentração de saponinas (Sphear \& Santos, 1996), substâncias tóxicas que podem estar atuando na inativação dos escleródios. Extratos aquosos de Chenopodium murale L., da mesma família de quinoa apresentaram atividade fungitóxica no crescimento micelial de S. sclerotiorum (Qasem \& Abu-Blan, 1995). A palha de Chenopodium spp. também contribuiu para o controle de Rhizoctonia solani Kühn (Dubey et al., 1983).

Observou-se uma maior eficiência da solarização do solo na presença de palha conferida pela redução da viabilidade dos escleródios a até $10 \mathrm{~cm}$ de profundidade, nos ensaios de campo em Piracicaba e Brasília. É importante enfatizar que a redução do número de escleródios a $5 \mathrm{~cm}$ pode ter grande impacto na incidência de doenças em cultivos subseqüentes, pois as estipes provenientes dos escleródios, que constituem a sustentação dos apotécios, possuem dimensão de, no máximo, 6,4 cm (Willian \& Western, 1965).

O controle mais eficiente quando se usa palha e solarização pode estar relacionado à degradação da matéria orgânica e liberação de substâncias tóxicas. Diversas reações podem ter ocorrido em cadeia conferindo a degradação química e microbiológica da palha de milho, que possivelmente conduziu à liberação de compostos tóxicos nas fases de vapor e líquida do solo, acumulando-se embaixo da cobertura plástica do solo solarizado. De acordo com Almeida (1986), materiais de alta relação C/N, na maioria constituída de lignina, como a palha de milho, podem, no processo de decomposição, ter a relação $\mathrm{C} / \mathrm{N}$ aumentada. Posteriormente, a relação tende a decrescer, chegando a uma situação estável. Esse processo de estabilização é lento, e leva à formação de compostos alelopáticos, de liberação gradativa. Segundo Putnam (1994), resíduos de milho, em cobertura morta sobre o solo, mesmo na ausência da solarização, apresentam substâncias de ação alelopática e tóxica. Uma hipótese é que o aquecimento associado ao teor de umidade alto do solo na prática de solarização possivelmente incrementa estes processos conferindo maior eficiência de controle da viabilidade do patógeno nos resultados obtidos. Gamliel \& Stapleton (1993a) demonstraram diferenças quantitativas e qualitativas nos componentes voláteis em solos aquecidos quando comparados aos não aquecidos, ambos adicionados com resíduos de repolho. Os solos adicionados com pequenas partículas de resíduos de repolho e aquecidos apresentavam maior concentração de álcool, aldeídos, sulfidos e isotiacenatos, que proporcionou a redução de propágulos de $P$. ultimum e $S$. rolfsii.

A simples deposição da palha de milho sobre o solo úmido e solarizado pode apresentar similaridades a processos rotineiros de laboratório em farmacologia utilizados para obtenção de óleos essenciais de diversas plantas medicinais e aromáticas. Indicando que a simples deposição dos resíduos sobre o solo pode ser uma prática facilitadora da disponibilização de diversos compostos fungitóxicos de resíduos de plantas, quando comparados à incorporação destes resíduos ao solo solarizado.

A maior eficiência do tratamento $P S$ também pode estar associada ao aumento de temperatura deste tratamento em relação a $S$. Os resultados de amplitude térmica na relação entre temperatura do solo e do ar indicaram que o acréscimo da palha de milho proporcionou o aumento da temperatura do solo. Resultados similares foram obtidos por Souza (2001), que ao incorporar resíduos de couve (B. oleracea var.acephala L.) ou torta de mamona (Ricinus communis L.) em solo solarizado observou a morte de $S$. rolfsii em apenas 14 dias, decorrente do aumento da temperatura do solo. E este aumento de temperatura foi observado nestes tratamentos até final do ensaio, aos 67 dias. Em contraste, segundo Chellemi et al. (1997), a incorporação de resíduo de repolho no solo associada à solarização não aumentou a temperatura do solo e não apresentou ganho de controle de $S$. rolfsii.

Uma hipótese para o aumento da temperatura do solo solarizado com cobertura de palha é que a coloração clara dos restos culturais pode refletir a radiação solar para a camada de ar adjacente, abaixo do plástico, elevando a temperatura. Em sistemas "fechados" como na solarização do solo este calor poderá ficar retido por maior tempo, influenciando a temperatura do solo abaixo da palha. Este fato indica a importância da não incorporação do resíduo ao solo na prática da solarização. Somente a sua deposição antes da cobertura com o plástico é suficiente para o controle.

A ocorrência de microrganismos potenciais de controle biológico foi observada nos tratamentos $S$ e $P S$, indicando a importância destes na eficiência da prática da solarização do solo. Os contaminantes mais freqüentes foram bactérias e fungos dos gêneros Penicillium, Fusarium, Trichoderma e Gliocladium. Esses resultados estão de acordo com Ghini \& Bettiol (1995), que relatam a maior facilidade de isolar agentes de controle biológico termotolerantes em solos em processo de solarização. Katan \& DeVay (1991) constataram que a solarização aumenta a população de microrganismos termotolerantes, como Aspergillus spp., Fusarium spp., Penicillium spp., Trichoderma spp., Bacillus spp. e Pseudomonas fluorescens Migula.

A maior variabilidade de contaminantes, que ocorre nos escleródios oriundos de solos solarizados com palha indica uma maior eficiência dessa prática. Evidências desse fato foram também observadas por Lodha et al. (1997). Segundo esses autores, solos solarizados incorporados com resíduos de crucíferas apresentaram temperaturas mais altas, o que promoveu o aumento da população de bactérias líticas antagonistas a $M$. phaseolina.

Conclui-se que a deposição de palha de milho sobre o solo e coberto com plástico poderá otimizar a solarização do solo na diminuição da viabilidade de escleródios de $S$. sclerotiorum, reduzindo o tempo para inativação de 90 para 


\section{L.C.L. Ferraz et al.}

60 dias, até uma profundidade de $10 \mathrm{~cm}$. Esse efeito, provavelmente, está ligado ao acréscimo da temperatura, à maior variabilidade de contaminantes, a disponibilização de compostos fungitóxicos presentes na palha de milho e no solo.

\section{REFERÊNCIAS BIBLIOGRÁFICAS}

ALMEIDA, F.S. Influência da cobertura morta do plantio direto na biologia do solo. In: Fancelli, A.L., Torrado, P.V. \& Machado, J. (Eds.) Atualização em plantio direto. Piracicaba. Fundação Cargill. 1986. pp.103-144.

BLOK, W.J., LAMERS, J.G., TERMORSHUIZEN, A.J. \& BOLLEN, G.J. Control of soilborne plant pathogens by incorporating fresh organic amendments followed by tarping. Phytopathology 90:253-259. 2000.

BOLAND, G.J. \& HALL, R. Index of plant hosts of Sclerotinia sclerotiorum. Canadian Journal of Plant Pathology 16:93-108. 1994.

CHELLEMI, D.O., OLSON, S.M., MITCHELL, D.J., SECKER, I. $\&$ McSORLEY, R. Adaptation of soil solarization to the integrated management of soilborne pest of tomato under humid conditions. Phytopathology 87:250-258. 1997.

DUBEY, N.K., KISHORE, N., SRIVASTAVA, O.P., DIKSHIT, A. \& SINGH, S.K. Fungitoxicity of some higher plants against Rhizoctonia solani. Plant and Soil 72:91-94. 1983.

FERRAZ, L.C.L. \& CAFÉ FILHO, A.C.Efeito da adição de fubá no meio de produção de escleródio e outros fatores influenciando na formação de apotécios de Sclerotinia sclerotiorum. Fitopatologia Brasileira 23:364-369. 1998.

GAMLIEL, A. \& STAPLETON, J.J. Characterization of antifungal volatile compounds involved from solarized soil amended with cabbage residues. Phytopathology 83:899-905. 1993a.

GAMLIEL, A. \& STAPLETON, J.J. Effect of chicken compost or ammonium phosphate and solarization on pathogen control, rhizosphere microorganisms, and lettuce growth. Plant Disease 77:886-891. 1993b.

GHINI, R. \& BETTIOL, W. Controle Físico. In: Bergamin Filho, A., Kimati, H. \& Amorim, L. (Eds.). Manual de Fitopatologia, $3^{\text {nd }}$ ed. Piracicaba. Ceres. 1995. pp.786-803.

KATAN, J. \& DeVAY, J.E. Soil Solarization. Boca Raton. Florida. CRC Press. 1991.
LIFSHITZ, R., TABACHINIK, M., KATAN, J. \& CHET, I. The effect of sublethal heating on sclerotia of Sclerotium rolfsii. Canadian Journal of Microbiology 29:1607-1610. 1983.

LODHA, S., SHARMA, S.K. \& AGGARWAL, R.K. Solarization and natural heating of irrigated soil amended with cruciferous residues for improved control of Macrophomina phaseolina. Plant Pathology 46:186-190. 1997.

NASSER, L.C.B., BOLAND, G.J. \& SUTTON, J.C. Meio de cultura semi-seletivo para detecção da viabilidade dos escleródios de Sclerotinia sclerotiorum. Fitopatologia Brasileira 20:376. 1995 (Resumo).

PINKERTON, J.N., IVORS, K.L., MILLER, M.L. \& MOORE, L.W. Effect of soil solarization and cover crops on populations of selected soilborne plant pathogens in western Oregon. Plant Disease 84:952960. 2000.

PORTER, I.J. \& MERRIMAN, P.R. Evaluation of soil solarization for control of root diseases of row crops in Victoria. Plant Pathology 34:108-118. 1985.

PUTNAM, A.R. Phytotoxicity of plant residues. In: Unger, P.W.(Ed.). Managing Agricultural Residues. London. Lewis. 1994. pp.285-342.

QASEM, J.R. \& ABU-BLAN, H.A. Antifungal activity of aqueous extracts from some common weed species. Annual Applied of Biology 127:215-219. 1995.

SMITH, J.L., PAPENDICK, R.I., BEZDICEK, D.F. \& LINCH, J.M. Soil organic matter dynamics and crop residue management. In: Metting Jr, F.B. (Ed.) Soil Microbiology Ecology. New York. Marcel Dekker. 1993. pp.65-94.

SOUZA, N.L. Sobrevivência de Fusarium oxysporum f. sp. lycopersici e Sclerotium rolfsii em solo solarizado incorporado com matéria orgânica. (Tese de Livre-Docência), Piracicaba. ESALQ/ Universidade de São Paulo. 2001.

SOUZA, N.L. Solarização do solo. Summa Phytopathologica 20:315. 1994.

SPEHAR, C.R. \& SANTOS, R.L.B. Potencial para produção de quinoa (Chenopodium quinoa) nos cerrados. Anais, VIII Simpósio sobre o Cerrado. Brasília, DF, 1996. pp.290-291.

WILLIAN, G.H. \& WESTERN, J.H. The biology of Sclerotinia trifoliorum Eriks. and other species of sclerotium-forming fungi. I. Apothecium formation from sclerotia. Annals of Applied Biology 56:253-260. 1965. 